\title{
Eine neue Art der Gattung Euplatinus Desbr.
}

\author{
(Col. Curc.)
}

\author{
Von Dr. L. Melichar in Bı̈̈nn.
}

\section{Euplatinus Boviei n. sp.}

Ovatus, convexus, niger, nudus, antennis, tibiis tarsisque rufotestaceis. Rostrum capite aequelongum, medio constrictum ibidemque breviter sulcatum, pterygiis divaricatis. Antennae fractae, scapo pronoti marginem anticam superante, apice breviter clavato, funiculi articulis duobus primis elongatis, tertio vix oblongo, caeteris moniliformibus, septimo clavam non adherente, clava breviter ovata. Oculi plani. Pronotum subtransversum, a latere distincte rotunáatum, antice modice plusque quam postice attenuatum, angulis posticis rectis, supra dense granulatum, linea longitudinali glabra obsoleta instructum. Scutellum nullum. Elytra humeris rotundatis, postice modice angustata apiceque conjunctim rotundata, convexa, subtilissime striato-punctata, spatiis subelevatis, densissime granulatis. Femora clavata, tarsi elongati, graciles, articulo tarsali postico elongato, valde gracili; unguiculis connatis. Long. $4 \mathrm{~mm}$. La t. $2.3 \mathrm{~mm}$. - M a roc co, Casablanca.

Beim ersten Anblicke glaubt man einen kleinen, schwayzen, rotbeinigen Otiorrhynchus aus der Gruppe mit nicht gezähnten Schenkeln vor sich zu haben, jedoch bei genauer Prüfung des Tieres beweisen die vollkommen verwachsenen Klauen der Beine, dass es kein Otiorrhynchu: sein kann. Desbrochers hat in Frelon 1909 p. 2 eine neue, der Gatt. Otiorrhynchus nahestehende Gattung Euplutinus mit der Art E. otiorrhynchoides aus Kleinasien, Adana, beschrieben, welche sich hauptsächlich durch die verwachsenen Klauen der Beine auszeichnet, ansonsten aber alle Merkmale der Gattung Otiorrhynchus aufweist. Ich glaube diese neue Art zu dieser Gattung rechnen zu dürfen, obgleich Deshrochers für seine Gattung „corpus ovatum tomentosum" antührt, was bei der neuen marokkanischen Art nicht zutrifft. Für die Aufstellung einer neuen Gattung sind aber keine wichtigen generischen Merkmale vorhanden und müsste daher in der

'Diagnose für diese Gattung die Erweiterung „corpus ovatum, tomensosum seu nudum * eintreten.

Schwarz, wenig glänzend, Fühler und Beine rötlichgelb; Rüssel so lang wie der Kopf, an der Spitze verbreitert, indem die Pterygien 
(-Dr. L. Melichar: Eine neue-Art der Gattung Euplatinus Desbr. 109

nach aussen erweitert sind, in der Mitte eingeschnürt und daselbst auf der Oberseite mit sehr kurzer, aber ziemlich tiefer Furche versehen. Fühlerschaft überragt stark den Vorderrand des Halsschildes; derselbe ist keulenförmig verdickt, die 2 ersten Glieder der Fühlergeissel länglich, die übrigen perlschnurartig, das 7. Glied von der Fühlerkeule getrennt, letztere kurz oval. Augen flach. Halsschild an den Seiten gerundet, nach vorn mässig, aber stärker als nach hinten verschmälert, die Hinterecken rechtwinkelig, oben dicht und fein gekörnt, mit einer undeutlichen glatten Mittellinie. Flügeldecken oval, nach hinten leicht verschmälert, an der Spitze gemeinschaftlich abgerundet, die Schultern abgerundet, oben dicht fein punktiert gestreift, die $Z$ wischenräume schwach gewölbt, mit feinen Körnchen dicht und unregelmässig besetzt. Beine mässig lang, Schenkel keulenförmig verdickt, die Tarsen schmal, das letzte Tarsenglied sehr schlank und lang, die Klauen verwachsen.

Ma r o c co, Casablanca; ein Exemplar $\left(\sigma^{\top}\right)$ von Hr. A. B ovie erhalten, welchem ich diese Art widme.

Die beiden Arten dieser Gattung unterscheiden sich folgendermassen:

Oberseite filzig behaart. Halsschild mit einem Mittèlkiel, Rüssel ohne Furche in der Mitte.

$\mathrm{K} l$ ein a sien. Adana.

otiorrhynchoides Desbr.

Oberseite kahl, schwarz, Halsschild fein granuliert, mit undeutlicher, glatter Mittellinie, Rüssel in der Mitte mit kurzer Längsfurche.

Mar o e c o, Casablanca.

Boviei n. sp. 


\section{$2 \mathrm{BHL}$ Biodiversity Heritage Library}

Melichar, Leopold. 1922. "Eine neue Art der Gattung Euplatinus DESBR. (Col. Curc.)." Wiener entomologische Zeitung 39, 108-109.

https://doi.org/10.5962/bhl.part.2571.

View This Item Online: $\underline{\text { https://www.biodiversitylibrary.org/item/43768 }}$

DOI: https://doi.org/10.5962/bhl.part.2571

Permalink: https://www.biodiversitylibrary.org/partpdf/2571

\section{Holding Institution}

Smithsonian Libraries

\section{Sponsored by}

Smithsonian

\section{Copyright \& Reuse}

Copyright Status: NOT_IN_COPYRIGHT

This document was created from content at the Biodiversity Heritage Library, the world's largest open access digital library for biodiversity literature and archives. Visit BHL at https://www.biodiversitylibrary.org. 